\title{
Automated Production Line Reliability Analysis of the Crankshaft Manufacturing Process
}

\author{
Abass Enzi ${ }^{1 *}$, Sardar Asif Khan ${ }^{2}$ \\ 1 Department of Production Engineering and Metallurgy, University of Technology, Baghdad, Iraq \\ 2 A. Leon Linton Department of Mechanical Engineering, Lawrence Technological University, Southfield, \\ MI 48075, USA \\ * Corresponding author's email: aenzi@ltu.edu
}

\begin{abstract}
The producer focuses on producing parts that match the customer's requirements during manufacturing the automotive engine parts. One of the essential automotive engine parts is a crankshaft used to translate movement from the pistons to the car axle. The crankshaft is a complex shape and difficult to produce accurate dimensions during the machining processes. Many machines are used to create the crankshaft. Therefore, many defects happen during the machining process, reducing reliability and increasing the manufacturing process's production cost. This paper focuses on analyzing failure data and reliability of the crankshaft production line that occurs during the manufacturing process of one year. The common failure associated with the manufacturing process were ring screw, unbalanced crankshaft, broken drill screw, hub machining error, mains part machining error, and setup error. The paper aimed to determine and analyze the best failure fit between the distribution methods, such as Weibull, normal, lognormal, and exponential. Also, the reliability, hazard rate, surviving quantity, and failure density were calculated to evaluate the current situation and predict the reliability of the production line. Results proved the skewness of the data was positive equal to 3.33 ; the last months had the highest production failure rate, which is $53.8 \%$, the normal method had a proper distribution of data depending on the Anderson-Darling (adj) values which is 1.367 when it compared with other methods, the normal method had the best fitting result depended on failure percentage, from $1 \%$ to $95 \%$ of the crankshafts production are expected to fail between 47.2676 and 1149.85 months respectively. The reliability of the production line decreased with manufacturing time increased. To reduce the failure and increase reliability, the maintenance system must be supported, analyze the sources that cause failure and downtime of the production line, continue the employee training system on an ongoing basis, and support the production line with modern technology. All analytical results and suggestions could be valuable to the production line to improve reliability and reduce the manufacturing process's failure.
\end{abstract}

Keywords: crankshaft production line, failure data analysis, distribution methods, reliability analysis.

\section{INTRODUCTION}

With the increase in demand for cars globally, factories have resorted to using automated factories to increase production, quality, and reduce manufacturing costs. As is known, automated production lines are a complex system. Therefore, one of the industrial challenges is to obtain a reliable manufacturing process. Furthermore, production lines apply reliability rules to predict maintenance and problems that occur during the manufacturing process. Reliability assessment depends on the data collected from the production line, such as the failure data, which is considered an essential tool for evaluating the production line's reliability by using statistical rules [1]. One of the main points that play as a tool for controlling the quantity and quality of production is reliability. The factors that affect reliability are the production line machines' general characteristics, the manufacturing process conditions, the tools available inside the plant that support the manufacturing process, 
and maintenance [2]. Due to the complexity of the production operation, the high distribution of process knowledge among operators, and the disparity of this knowledge (material selection, heat treatment processes, machining processes, surface treatment processes, quality processes), online control is not reliable nor objective [3]. The design reliability has many methods to estimate the production process, production line, and manufactured parts' product life efficiency and safety. In the plants, many failures happen, which leads to losing control of the manufacturing process. Therefore, the reliability design should be used to determine the safety area and critical area.

As is known, there are a lot of automated and non-automated failures happening in the production line while producing the parts. Some failures occur due to manufacturing variables, machines, and workpiece material. So, researchers use statistical and reliable rules to understand manufacturing and identify factors that increase productivity and reduce the problems that occur in production. Most plants focus on studying defects that reduce productivity reliability. Therefore, if manufacturing defects are not addressed, parts that do not meet the required specifications will be produced over time. Applying some reliability rules during manufacturing operations provides high productivity, low manufacturing cost, and plant improvement.

Accorsi et al. [4] integrated plant manufacturing using computerized tools to control maintenance management systems built on plant failure history to increase reliability, reduce maintenance, and reduce downtime during the manufacturing process. The platform proposed evaluated the potential unexpected failure in the production line in terms of downtime and other variables that affect the production process. Also, one of the important points addressed by the proposed platform was to increase the production rate by reducing the time required for maintenance by $20 \%$, leading to increased productivity, increased Mean Time between Failures (MTBF), and decreased Mean Time to Repair (MTTR). Dos Reis et al. [5] studied the reliability of an automotive production line of machining and assembly by implementing total productive maintenance. Researchers began by analyzing the types of failure in the production line, and then the proposed plan was implemented by developing preventive plans to avoid failure during the manufacturing process. Five machines were selected from the production line to apply the proposed method to increase production efficiency. Several steps have been applied to improve the production line's efficiency and avoid failure during the manufacturing process. The results approved $18 \%$ the operating process increased after applying improving plans. Ribeiroa et al. [6] worked to increase the reliability of the production line of an automotive production system by monitoring faults that occur during the manufacturing process. A preliminary analysis process is performed for the production line to identify the main problems by observing Mean Time between Failures (MTBF), Mean Time to Repair (MTTR), Overall Equipment Efficiency (OEE), and Availability (A). After the identified problems, a plan was developed and implemented to identify the main causes of downtime and failure in the production line, such as using $5 \mathrm{~S}$ tools, good management, maintenance scheduling, and developing workers' skills through continuous training programs. After implementing the proposed plan, the results proved increasing MTBF, MTTR, and availability. Jasiulewicz-Kaczmarek and Gola [7] presented the possibility of using Maintenance 4.0 to integrate new methods in different manufacturing systems in planning, implementation, and monitoring the manufacturing processes in modern manufacturing companies. This research focused on supporting the maintenance system through Maintenance 4.0, which replaced the old methods to support the production process, increase reliability, reduce downtime during the manufacturing process, increase safety, and reduce costs. Conclusions proved the Maintenance 4 technologies could be applied in the parts life cycle to reduce downtime, services, and aftersales to build a strong relationship with customers and reduce failures. Soltanali et al. [8] addressed the reliability evaluation through failure behavior of the automotive production line. Reliability analysis included statistical analysis and Monte Carlo simulation, and the analysis process was carried out after collecting data and assessing the influencing variables. The statistical reliability estimation indicated that the bottleneck was one of the priorities affecting the manufacturing process. The results proved Monte Carlo simulation gave prediction with high accuracy of reliability. Also, an improvement of the production line was made to the reliability of maintenance to reduce downtime depending on the proposed methods. Zhang [9] evaluated the piston production line's reliability by statistically analyzing the repair and failure data. The production line data was collected 
for fifteen months. A failure losses-based importance measure (FLBIM) method was proposed to determine reliability defects that depended on the failure measure of the production line. The results proved Mean Time between Failures (MTBF) of the production line machines was smaller than manual operation due to the heavier workload and some parts added to convert the manufacturing process to automation, so that causes frequent faults that lead to low reliability. Improper maintenance and tool change recorded $28.59 \%$ of the total failures, and MTBF was $6.03 \mathrm{~h}$ of the production line. Therefore, tools, equipment, and sensors used during manufacturing should change before failure to avoid downtime in the production line.

Mass production lines always produce defects reducing quality, productivity, and increasing production costs. Therefore, in this paper, the crankshaft production line's failure data were analyzed using statistical methods. The results were proved the normal distribution has the lowest Anderson-Darling value compared to other distribution methods. Reliability was also calculated to assess the current and future performance of the production line. The research also aims to find the best analytical method that gives a clear picture to describe the manufacturing process failure.

\section{CRANKSHAFT PRODUCTION LINE DESCRIPTION}

Complex mechanical parts such as crankshafts, later attached to the complex machines, are produced following a step-by-step process that usually lasts for hours depending on the part complexity. The crankshaft is not easy to manufacture; the casting or forging is used to create a crankshaft. Critical aspects of this process are the presence of surface defects due to: fails during the machining process, irregularities in external dimensions due to malfunction of machining stations, excess of surface roughness due to failure in surface treatment processes, high response time while correcting process parameters to mitigate scrape, and practical impossibility to follow parts during their useful life [3]. The machining process of crankshaft involves many machines. Each operation sometimes has more than one machine working together, and the cycle time changes from one operation to another, depending on the process type. The crankshaft manufacturing process's production line machines consist of twenty-one operations like rough machining, turning, fillets and holes machining, finishing, balancing, washing, etc. see Figure 1. After completing each step of the crankshaft machining process, the checking process starts to measure dimensions and machining quality using specific gauges before sending it to the following machining process. The balancing test is one of the significant steps, so in this step, some material will be removed from the crankshaft web zone to make the crankshaft stable during the rotation process.

As mentioned earlier, the production line for manufacturing the crankshaft consists of many processes using different machines depending on the manufacturing process type. The number of machines used for each operation ranges

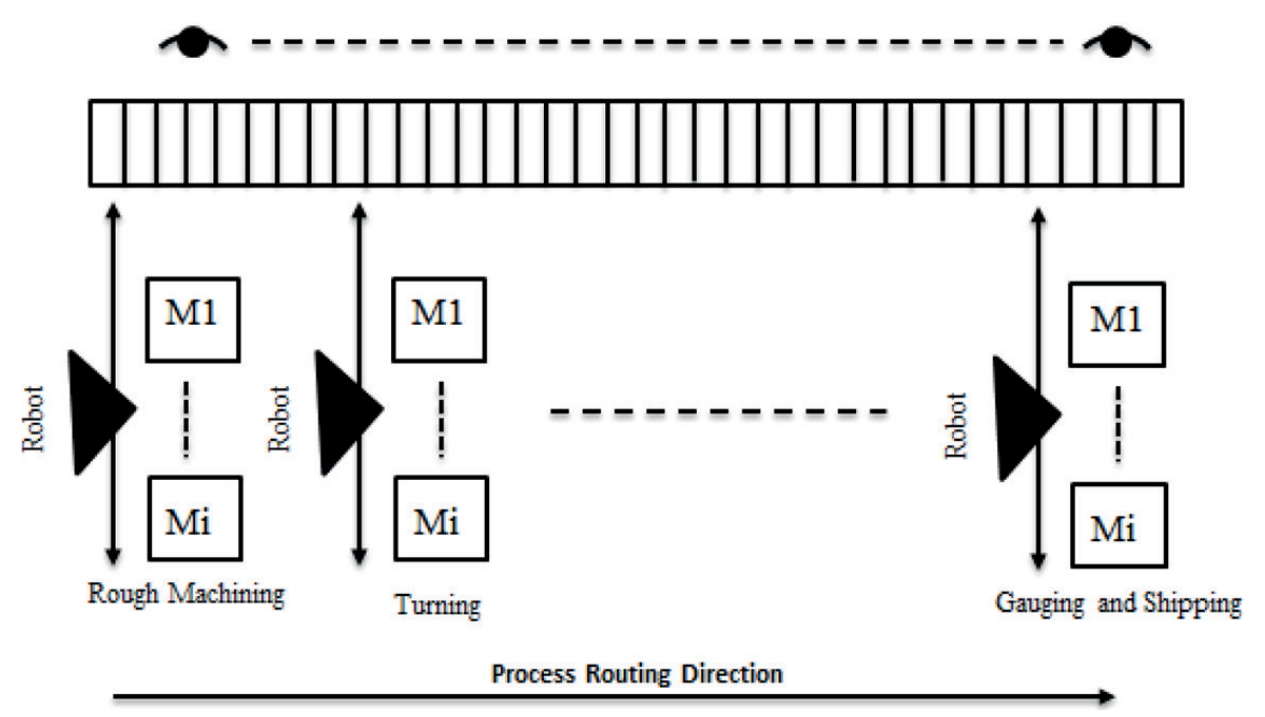

Fig. 1. Production line diagram of the crankshaft manufacturing 
from two to five. Besides, the crankshaft's transport in every step of the manufacturing process is automated using robotics. The cutting process variables are determined by relying on the cutting rules by considering the required surface roughness, machining tolerances, cutting type, cutting tools material, coolant, etc. Table 1 describes all the production line operations like manufacturing steps, the number of parts produced per cycle, and the time required to make each piece.

Furthermore, the operating time varies from one operation to another because the time required to run depends on the type of operation, the number of parts to be operated, and the number of machines available for each operation step. This paper uses a casting process to create a crankshaft, and the production line will produce 60 parts/ hours. After receiving the crankshaft from the casting plant, the manufacturing operation will start. Figure 2 shows the crankshaft parts, and some of the components have complex areas not accessible to produce, such as the main journal, crank web, crank ends, oil bore, and web fillets.

Many plants have implemented a new technique to increase productivity and improve the product through continuous research on developing production lines in industrialized countries. Automated systems, new strategies, robotics, software, etc., are used in the production line to deliver the product to the customer on time, produce a part with high quality, and reduce manufacturing time and operation cost. For every single step of the manufacturing process, there is a product inspection to determine the differences
Table 1. Crankshaft production line description

\begin{tabular}{|l|c|c|}
\hline \multicolumn{1}{|c|}{ Description } & $\begin{array}{c}\text { Pieces/ } \\
\text { Cycle }\end{array}$ & $\begin{array}{c}\text { Cycle Time } \\
\text { (sec) }\end{array}$ \\
\hline CNC (Rough Ends Machining) & 2 & 264.0 \\
\hline Mill (Rough Mains) & 1 & 66.0 \\
\hline Mill (Rough Pins) & 1 & 132.0 \\
\hline $\begin{array}{l}\text { Turn Broach } \\
\text { (Semi-Finish Mains, Flange } \\
\text { Dia., Flange Face) }\end{array}$ & 1 & 198.0 \\
\hline Mill (Semi-Finish Pins) & 1 & 66.0 \\
\hline Washer & 1 & 66.0 \\
\hline Fillet Roller & 1 & 66.0 \\
\hline CNC (Oil Hole) & 3 & 396.0 \\
\hline CNC (Finish Ends Machine ) & 2 & 264.0 \\
\hline Ginder Multi-Wheel (Mains) & 1 & 66.0 \\
\hline Grinder & 1 & 66.0 \\
\hline Inline Gage (Mains Post) & 1 & 66.0 \\
\hline Grinder (Pins) & 1 & 132.0 \\
\hline Inline Gage (Pins, Thrust & 1 & 66.0 \\
\hline Walls, Flange) & 1 & 66.0 \\
\hline CNC (Keyway, Final Bore) & 1 & 66.0 \\
\hline Balancer & 1 & 66.0 \\
\hline Ring Assembly & 1 & 66.0 \\
\hline Balancer & 1 & 66.0 \\
\hline Polisher & 132.0 \\
\hline Washer & 1 & 66.0 \\
\hline Final Gage \& Classification & 1 & \\
\hline
\end{tabular}

between input and output during manufacturing to determine whether the product is within the required limits. This difference is caused by machine, installation, and manufacturing variables that produce defects in the work. Employees' goal

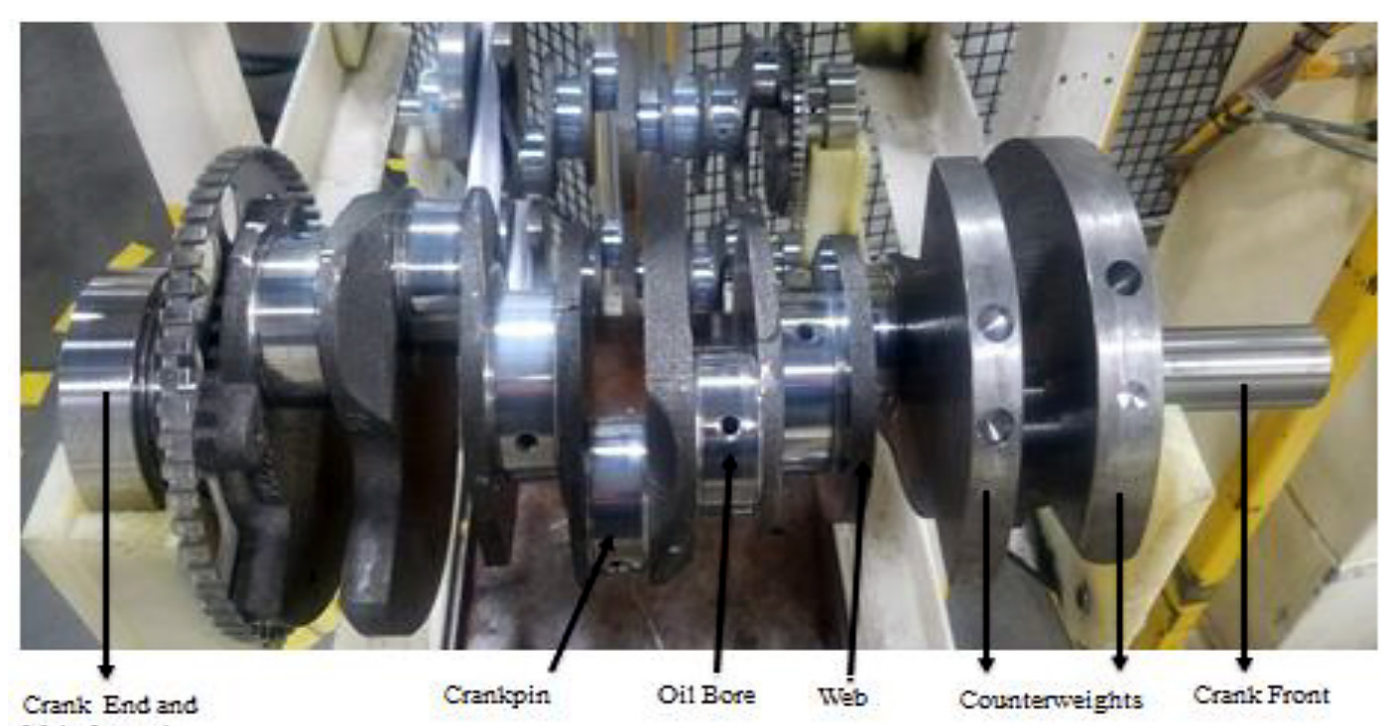

Fig. 2. Crankshaft that produced of the production line 
is to manufacture a product and match customer requirements, which is considered a great sign of the manufacturing process. Critical measures to accomplish the manufacturing process with minimal errors, increase production, reduce scrap, and the manufacturing process's highest organization indicate that the production line has the highest reliability to finish the work within the specified time [10]. One of the critical points during the production process is to increase the speed of production, taking into consideration the quality of throughput. Therefore, the decrease in reliability leads to an increase in the machining cost, an increase in the number of failed parts, a decrease in the production line's working efficiency through increased downtime, and a reduction in safety [1].

\section{FAILURE REASONS OF THE CRANKSHAFT MACHINING PROCESS}

A manufacturing process is an interaction between the machines and the workpiece on the production line to produce the required parts. Also, the operations are controlled by predefined operating variables to provide a high-quality product. Therefore, several factors affecting the manufacturing process should be considered to avoid machining defects [11]. An operating system includes machines, tools, and machining variables. All the manufacturing systems are inspected, and this process should be periodic. Also, the workpiece should be checked before sending it to the production line. The checking process includes material inspection, dimensions, the procedures required before or after the machining, etc. Different strategies are applied to the workpiece to avoid failure of operations, machines, and tools used in the manufacturing process, such as heat treatment, coating, etc. Furthermore, employees in the plants consider the core of the manufacturing process. Therefore, the plant employees should follow all rules that maintain the required product quality (see Fig. 3).

The majority of production lines for mass production are connected to a system of sensors and integrated communications. The strategy aims to collect all data and information about machines, tools, product quality, productivity, etc. Due to the machining process's many parts and factors. Therefore, some techniques and programs must extract information and diagnose the production's fault from the measured data [11]. Some points should be taken into account during the manufacturing process to reduce downtime. Those points are machine description, observing failure type, failure reasons, failure effects, failure severity, the probability of failure, criticality index, and corrective action [12].

The automotive crankshaft production line is a case study used in this paper to analyze machining processes' reliability of crankshaft. Errors in the machining process are widespread. For this reason, the project will study manufacturing defects of crankshaft machining to reach high reliability during manufacturing. The production line operates 24 hours in two shifts, each one 10 -hour, and the remaining time is used to prepare for the next day. The production machines' input variables are manufacturing parameters (cutting speed, feed rate, metal removal rate per minute), and the machining results are dimension accuracy and surface roughness. Several failures affect parts quality during the manufacturing process, resulting from a machine or manufacturing tools, workpiece, or manufacturing parameters. These failures are ring screw produced because

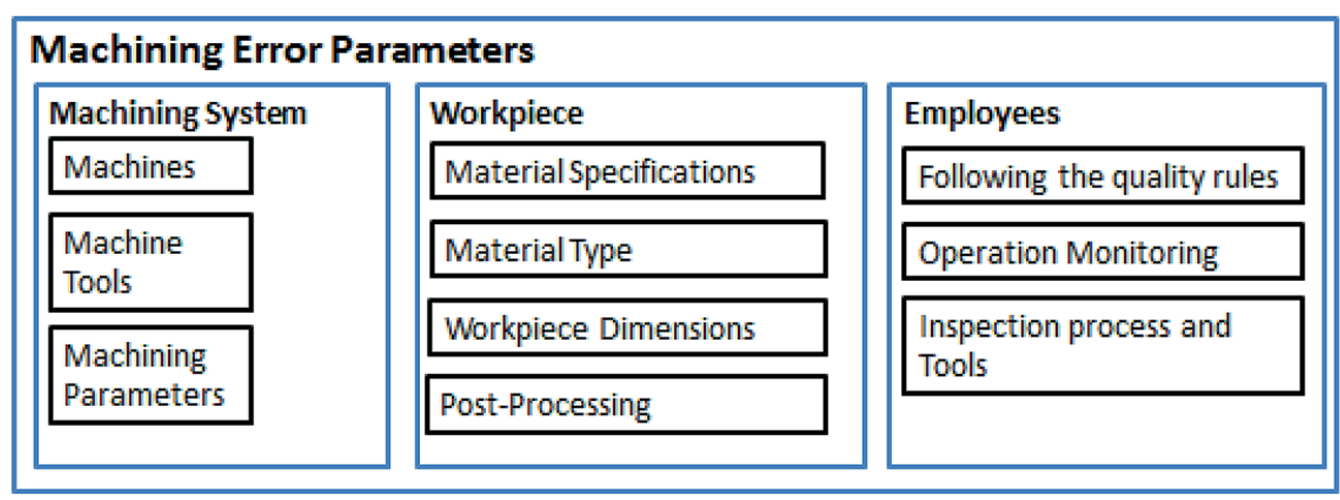

Fig. 3. Essential elements of the manufacturing process must be taken into consideration to avoid the machining error 
of machining error, the unbalanced crankshaft is produced because of some material should removed from the crankshaft, pins part error is created because of over or under machining, broken drill screw is made because of the cutting tool failed during the machining process, hub part is produced because of machining error, mains part is created because of over or under machining, and setup error is made because of an error in the workpiece setup and/or an error in the manufacturing process variables. Furthermore, all types of product failures are present in the company with all information about failure, such as time, machine number, time is taken for maintenance, etc.

All data for production failure were collected for one year, knowing that the production line consists of 20 stations. The total number of machines used to manufacture the crankshaft equals 30 machines. There are many types of manufacturing failures for the crankshaft that lead to rejecting the products. Figure 4 shows that the crankshaft product's essential types of failure during machining on the production line are ring screw, unbalanced, pins, broken drill, hub, mains, and set up. Maintenance officials inside the factory are responsible for maintaining any malfunction in the production line that leads to product failure or reduces productivity. The engineers will also analyze the cause of failure and the reasons that cause it to avoid its occurrence or recurrence.

Figure 5 shows the Pareto chart of the failure machining of the crankshaft production line. The Pareto chart results proved that the highest failure percent occurred in December, which is $15.4 \%$. Also, more than half of the failure rate occurred in the last four months of the year, which is $53.8 \%$. During the manufacturing process, there are two types, which are simple failure and complex failure. The first type can be easily identified and maintained, while the second type is challenging to locate and requires high experience to identify and maintain. Therefore, it is essential to determine the type of failure to analyze the causes that led to the failure (the process of study and analysis is done for all kinds of failure) to increase production and product quality. Mean time between failures (MTBF) [13] can be defined as elapsed between failures inherent during production line operation and used for repairable parts. The MTBF is calculated from Eq. 1 by using total uptime and the number of breakdowns.

$$
\text { MTBF }=\frac{\text { Total uptime }}{\text { Number of Breakdowns }}
$$

By observing the crankshaft manufacturing process and the failure that occurred during the operation process, some failures require less than an hour to be repaired. Others require more than an hour, taking into account the type of malfunction needed to be repaired. Figure 6 shows the histograms; it shows the relationship between MTBF and failure frequency (every month). The purpose of the histograms was to observe and analyze failures that happened on the production line. From the results, $0.5 \mathrm{hr}$ of MTBF had the most considerable failure frequency, and $8 \mathrm{hrs}$ of MTBF had the shortest failure frequency. Table 2 shows the descriptive statistics of the production line to MTBF, which includes the length of time used to obtain the data (count), the mean of the

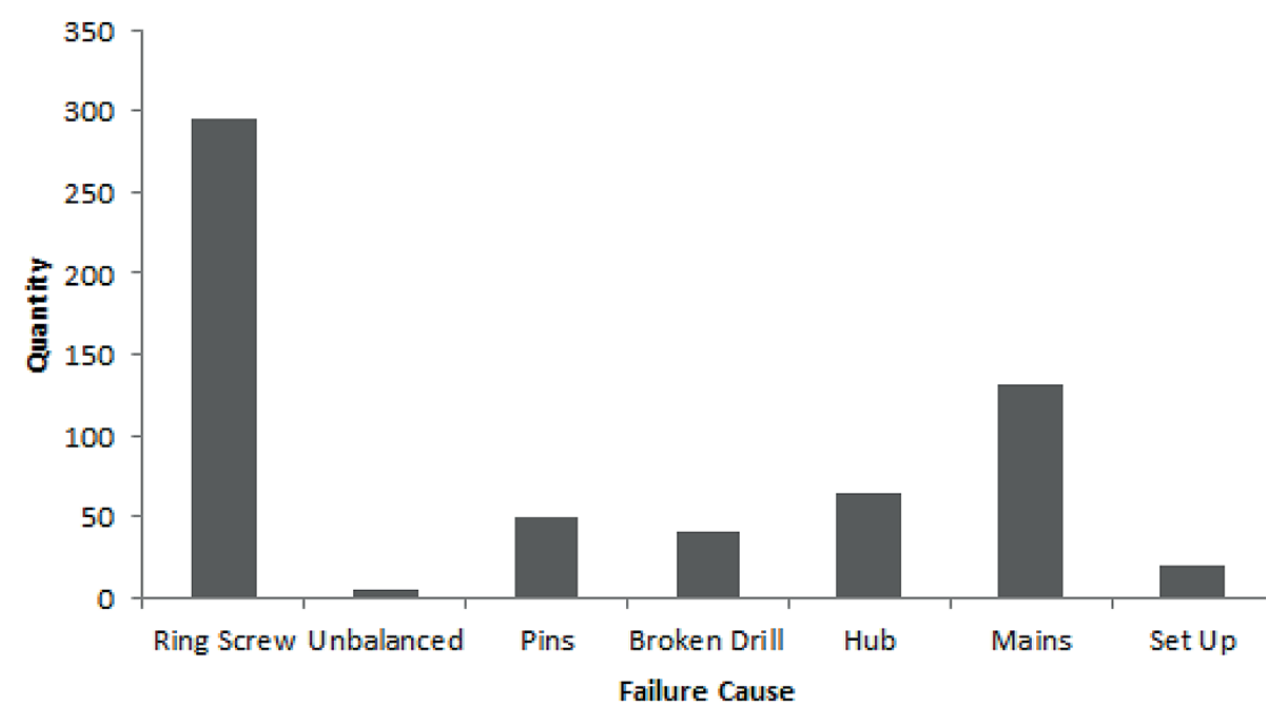

Fig. 4. Failure types that happen during machining the crankshaft 


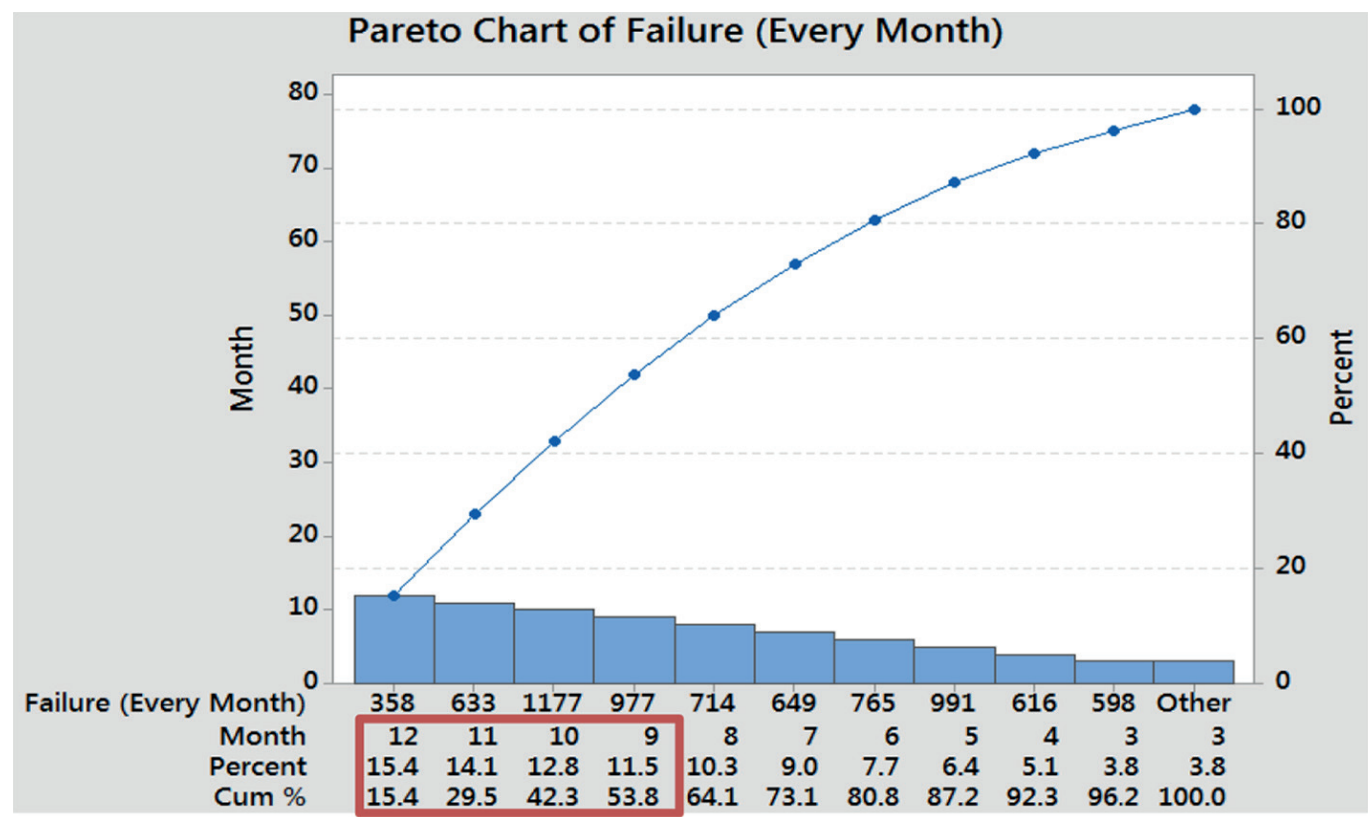

Fig. 5. Pareto diagram of the failure quantity for the crankshaft production line

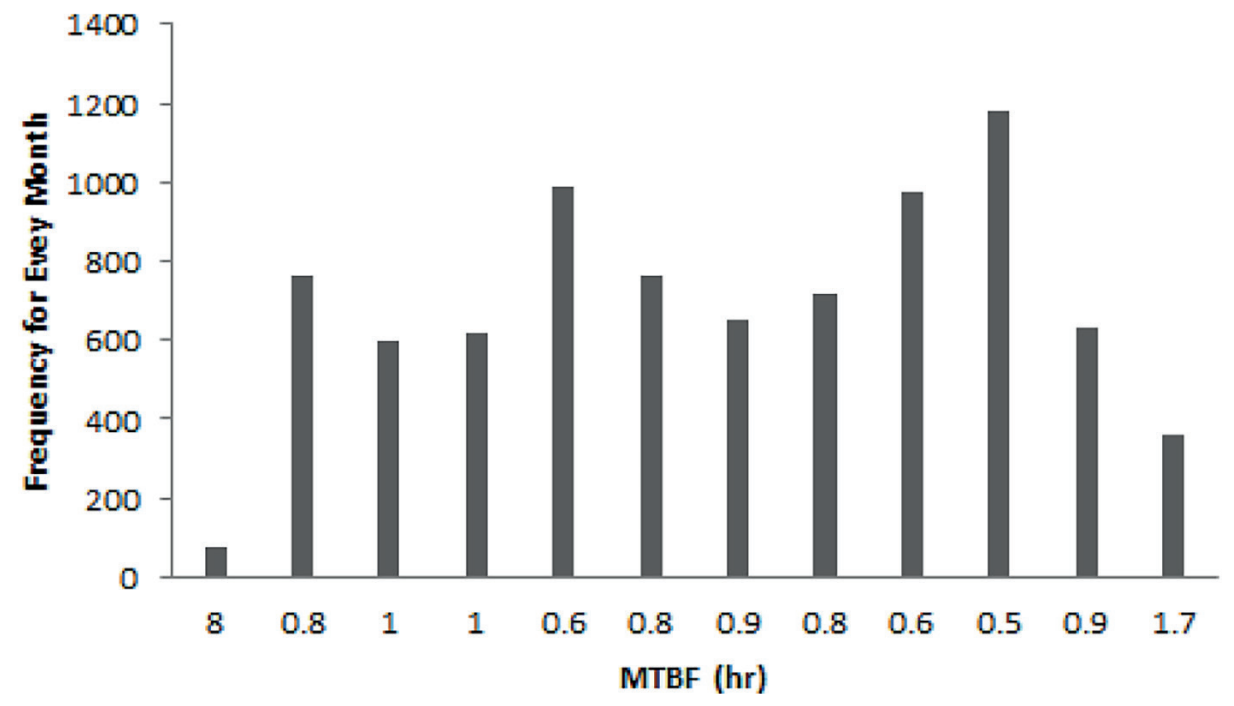

Fig. 6. MTBF histogram for the crankshaft production line

Table 2. Display the production line descriptive statistics

\begin{tabular}{|c|c|c|c|c|c|c|c|}
\hline Variable & Count & Mean & StDev & Minimum & Maximum & Skewness & Kurtosis \\
\hline MTBF & 12 & 1.502 & 2.069 & 0.530 & 8.000 & 3.33 & 11.31 \\
\hline
\end{tabular}

data used to analyze the production line errors, the standard deviation to find the distribution of the data used around the mean, the minimum and maximum data of MTBF, and skewness and kurtosis to check the distribution is positive or negative. The results proved the standard deviation was close to the mean, and the skewness of the MTBF is positive (the proper tail distribution is longer than the left side).

\section{PROBABILITY DISTRIBUTION METHODS}

Probability distributions consider the mathematical basis of statistical theories used in industrial, production, manufacturing, etc. While analyzing the production lines' manufacturing processes, some mathematical probability functions are used to analyze the results. The probability distribution is defined as a random phenomenon 
of the probability of a particular event during the operation process. There are many methods of probability distributions used to observe and analyze plant data. Also, those methods use in reliability and six sigma fields. When defining any probability distributions method, one should consider limitations and distribution parameters such as scale, shape, source, etc. There are four distribution methods used in this paper to describe density functions (Table 3 ). Table 4 shows reliability, mean, and variance for all distribution methods used to describe machining failure. During the calculation, the variables must be defined previously. Some variables are used in the estimate, depending on the method type. The variables are shown in the nomenclature in Table 3.

\section{Distribution methods}

It must be focused on studying and analyzing critical points to increase the manufacturing process's efficiency. The points are production rate, MTBF, MTTR, reliability, bottleneck, regular maintenance, and minimizing material waste during manufacturing. By looking at some of the manufacturing processes, productivity is good when it is $75 \%$. It is also possible to increase production by focusing on the previously mentioned points and improving the production line. Some researchers [2] explained some essential issues related to increasing the productivity of production lines. The first point, increasing the machining of the production line. In this step, sometimes you need to change the production line by removing or adding some machine equipment, considering the bottleneck during the manufacturing process. Therefore, this step is sometimes complicated to implement. The second point is to reduce the errors that occur in the production line and the manufacturing process. In this step, space is needed along the production line that is called a buffer between the machines to avoid stopping the production line's work in the event of any malfunction in a machine in the production line. The third point, treating repeated failure and reducing maintenance time. This step is accomplished through a continuous follow-up of the production line to address and identify the common problems.

The distribution probability plot analyzes the failure data using different methods to select the best fits with minimum failure. The method selection that gave better results depends on the Anderson-Darling (adj) values and distribution data around the diagonal line. Four methods are used to analyze the failure data: Weibull, exponential, lognormal, and normal. Figure 7 shows

Table 3. Density functions of distribution methods [14, 15]

\begin{tabular}{|c|c|l|}
\hline Method & Formula & \multicolumn{1}{|c|}{ Nomenclature } \\
\hline Exponential & $f(t)=\lambda \exp (-\lambda x), t>0$ & $\begin{array}{l}\lambda=\text { Parameter Distribution } \\
t=\text { Variable }\end{array}$ \\
\hline Normal & $f(t)=\frac{1}{\sigma \sqrt{2 \pi}} \exp \left[-\frac{1}{2}\left[\frac{t-\mu}{\sigma}\right]^{2}\right]$ & $\begin{array}{l}\mu=\text { Mean } \\
\sigma=\text { Standard deviation }\end{array}$ \\
\hline Lognormal & $f t(t)=\frac{1}{\mathrm{ts} \sqrt{2 \pi}} \exp \left[-\frac{1}{2 s^{2}}\left[\ln \frac{t}{t_{\text {med }}}\right]^{2}\right] \geq 0$ & $\begin{array}{l}t_{\text {med }} \text { = Median time to failure } \\
s=\text { Shape parameter }\end{array}$ \\
\hline Weibull & $f(x)=1-\exp \left[-\left[\frac{t-\gamma}{\theta}\right]^{\beta}\right]$ & $\begin{array}{l}\beta=\text { Shape parameter } \\
\theta=\text { Scale parameter } \\
\gamma=\text { Location parameter }\end{array}$ \\
\hline
\end{tabular}

Table 4. Reliability, mean, and variance functions of distribution methods [14, 15]

\begin{tabular}{|c|c|c|c|}
\hline Method & Reliability & Mean & Variance \\
\hline Exponential & $\mathrm{e}^{-\lambda \mathrm{t}}$ & $\frac{1}{\lambda}$ & $\frac{1}{\lambda^{2}}$ \\
\hline Normal & $1-\Phi\left(\frac{\mathrm{t}-\mu}{\sigma}\right)$ & $\mathrm{Ln} \mathrm{t}$ med & $\mathrm{s}^{2}$ \\
\hline Lognormal & $1-\Phi\left(\frac{1}{\mathrm{~s}} \ln \frac{\mathrm{t}}{\mathrm{t}_{\mathrm{med}}}\right)$ & $\mathrm{t}_{\text {med }}^{2} \mathrm{e}^{\mathrm{s}^{2} / 2} \mathrm{e}^{\mathrm{s}^{2}}\left[\mathrm{e}^{\mathrm{s}^{2}}-1\right]$ \\
\hline Weibull & $\mathrm{e}^{\left(\frac{\mathrm{t}}{\theta}\right)^{\beta}}$ & $\theta \Gamma\left[1+\frac{1}{\beta}\right]$ & $\theta^{2}\left[\Gamma\left(1+\frac{2}{\beta}\right)-\left(\Gamma\left(1+\frac{1}{\beta}\right)\right)^{2}\right]$ \\
\hline
\end{tabular}


the distribution data of the crankshaft failure data for 12 months. The results proved the normal distribution given a lower value equal to 1.367 and had better data distribution around the diagonal line than the other methods. For reasons explained previously, the normal distribution method will be used to analyze the manufacturing process. Figure 8 gives the plant's engineers
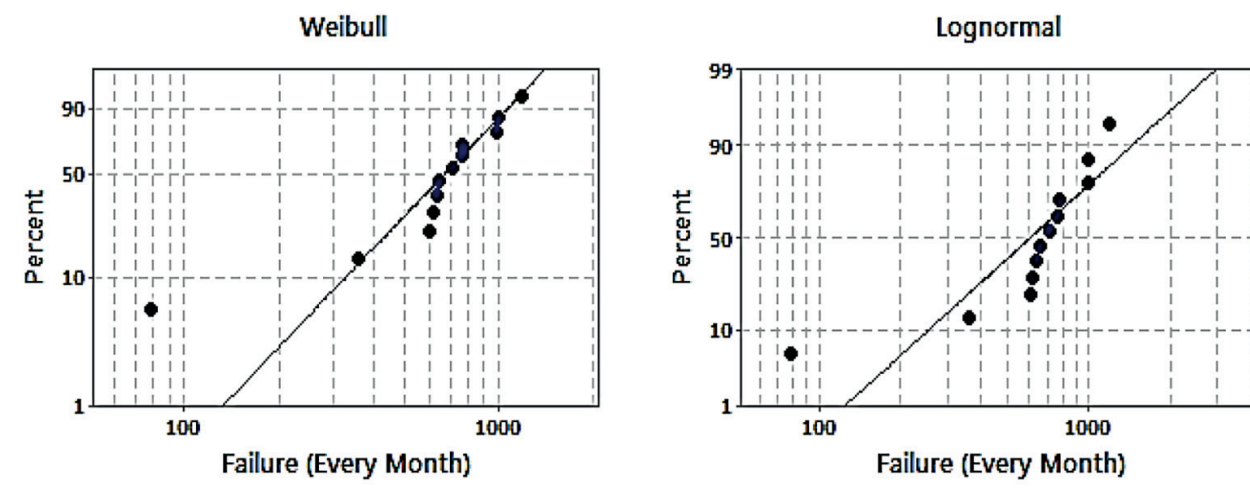

Anderson-Darling (adj) Weibull 1.544 Lognormal 2.168
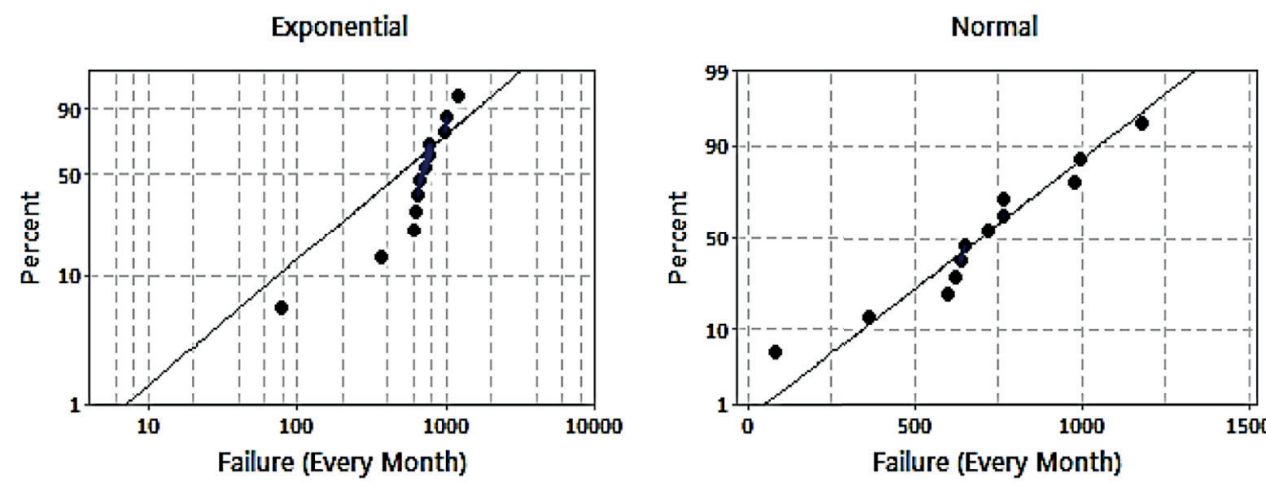

Exponential 3.142 Norma 1.367

Fig. 7. Probability plots of distribution methods for the crankshaft production line failures
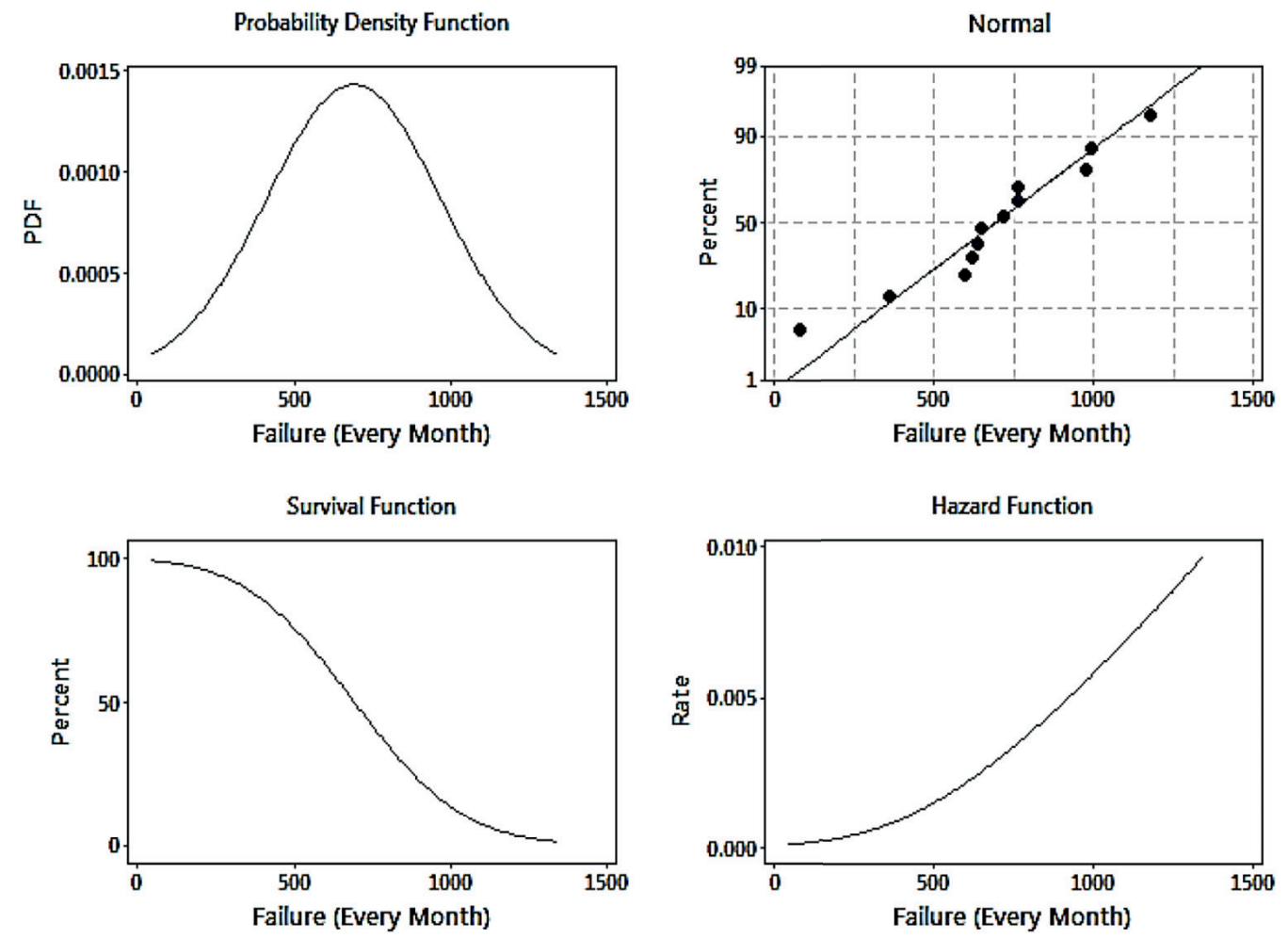

Fig. 8. Normal distribution plot of the crankshaft production line failures 
essential details about probability density, distribution data, survival, and hazard functions. From analyzing the results, the survival function started decreasing after 250 months, and the hazard function started increasing after 250 months. Figure 9 shows the probability plot by using the normal method with a $95 \%$ confidence interval. The plot proved all the data around the diagonal line and between the $95 \%$ confidence interval lines.

Table 5 shows the failure percentage; the results show $1 \%$ of the crankshafts production is going to fail in 47.268 months; $5 \%$ of the crankshafts production is going to fail in 236.481 months; $10 \%$ of the crankshafts production is going to fail in 337.35 months; $25 \%$ of the crankshafts production is going to fail in 505.898 months; $50 \%$ percent of the crankshafts production is going to fail in 693.167 months; $75 \%$ percent of the crankshafts production is going to fail in 880.435 ; $95 \%$ of the crankshafts production is going to fail in 1149.85 months. Also, Figure 10 normal method has the best fitting result and is recommended compared with lognormal, exponential, and Weibull.

\section{Reliability analysis of the crankshaft production line}

The customers need to produce parts that have good quality at the best price. Therefore, the supplier should focus on customer requirements to reduce shortfalls that happen in production. The engineering approach that integrates all the consumer requirements and determinants to produce a functional product is system engineering. It is known as the designer's goal to provide

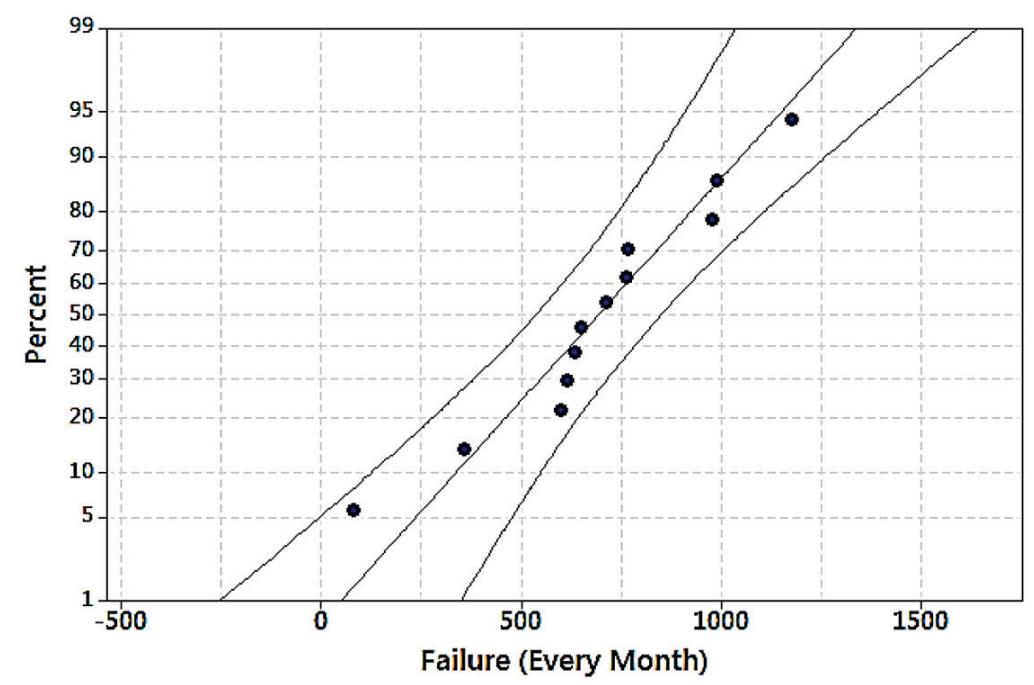

Fig. 9. Probability plot of the normal distribution method with $95 \%$ confidence interval

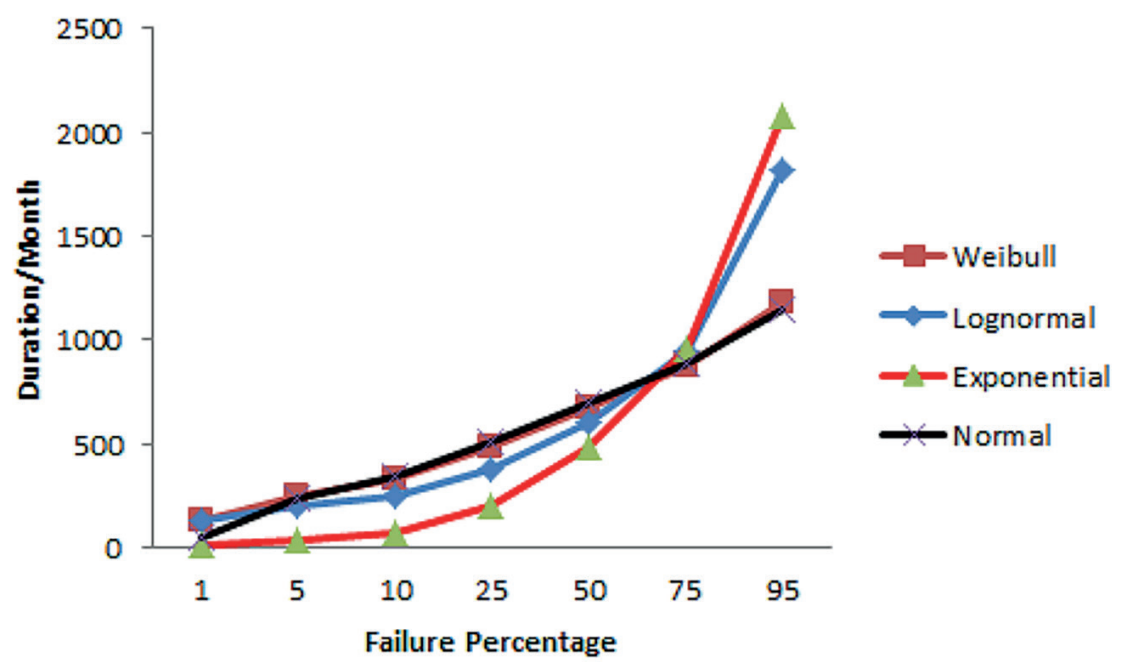

Fig. 10. Comparison between four distribution methods 
Table 5. Failure percentiles values relate to distribution methods

\begin{tabular}{|c|c|c|c|c|c|}
\hline \multirow{2}{*}{ Distribution } & Duration/Month & Standard & $95 \%$ & Normal & $\mathrm{Cl}$ \\
\hline & Percent & Percentile & Error & Lower & Upper \\
\hline Weibull & 1 & 131.733 & 61.8173 & 52.5120 & 330.469 \\
\hline Lognormal & 1 & 122.863 & 46.3428 & 58.6616 & 257.327 \\
\hline Exponential & 1 & 6.96656 & 2.01107 & 3.95638 & 12.2670 \\
\hline Normal & 1 & 47.2676 & 154.294 & -255.143 & 349.678 \\
\hline Weibull & 5 & 246.373 & 80.0016 & 130.374 & 465.578 \\
\hline Lognormal & 5 & 195.122 & 58.6419 & 108.264 & 351.663 \\
\hline Exponential & 5 & 35.5548 & 10.2638 & 20.1919 & 62.6064 \\
\hline Normal & 5 & 236.481 & 122.939 & -4.47469 & 477.437 \\
\hline Weibull & 10 & 324.840 & 85.4716 & 193.955 & 544.047 \\
\hline Lognormal & 10 & 249.688 & 66.0218 & 148.705 & 419.247 \\
\hline Exponential & 10 & 73.0324 & 21.0826 & 41.4758 & 128.599 \\
\hline Normal & 10 & 337.350 & 108.162 & 125.356 & 549.345 \\
\hline Weibull & 25 & 477.780 & 87.4781 & 333.717 & 684.032 \\
\hline Lognormal & 25 & 377.001 & 81.8390 & 246.357 & 576.927 \\
\hline Exponential & 25 & 199.412 & 57.5652 & 113.248 & 351.133 \\
\hline Normal & 25 & 505.898 & 88.7983 & 331.856 & 679.939 \\
\hline Weibull & 50 & 669.762 & 85.8659 & 520.947 & 861.089 \\
\hline Lognormal & 50 & 595.887 & 116.755 & 405.867 & 874.871 \\
\hline Exponential & 50 & 480.467 & 138.699 & 272.862 & 846.026 \\
\hline Normal & 50 & 693.167 & 80.1492 & 536.077 & 850.256 \\
\hline Weibull & 75 & 874.071 & 96.9177 & 703.339 & 1086.25 \\
\hline Lognormal & 75 & 941.857 & 204.457 & 615.471 & 1441.33 \\
\hline Exponential & 75 & 960.933 & 277.397 & 545.723 & 1692.05 \\
\hline Normal & 75 & 880.435 & 88.7983 & 706.394 & 1054.48 \\
\hline Normal & 95 & 1175.13 & 154.747 & 907.809 & 1521.16 \\
\hline Lognormal & 95 & 1819.79 & 546.920 & 1009.72 & 3279.76 \\
\hline Exponential & 95 & 2076.54 & 599.446 & 1179.29 & 3656.46 \\
\hline Normal & 95 & 1149.85 & 122.939 & 908.896 & 1390.81 \\
\hline
\end{tabular}

a product that satisfies the level of performance required by taking into account the total cost of the product should be acceptable. Sometimes, the product's manufacturing cost increases by adding some operations that improve product performance and reliability.

Furthermore, the four characteristics used to enhance product performance are reliability, availability, maintainability, and supportability. Analysis reliability (engineering, economical, and risk) should be considered in the first steps of the design process to achieve the optimum life cycle and better product results. The purpose of the analysis is to determine the best way to increase profits by improving and evaluating the product's lifetime. Therefore, to obtain the product's best life, this happens through reliability analysis and finding alternative measures to achieve the product's best functional performance [16].
The empirical method analyzes the free and nonparametric methods to determine the failure probability, reliability, hazard rate, and failure of the crankshaft production line. The statistical prediction is simply a way to analyze the manufacturing operations, which effort to predict and calculate reliability $\mathrm{R}(\mathrm{t})$, failure rate $\mathrm{F}(\mathrm{t})$, and hazard rate $\mathrm{h}(\mathrm{t})$. The equations below are used to calculate reliability $\mathrm{R}(\mathrm{t})$, cumulative failure $\mathrm{CF}$, hazard rate $\mathrm{h}(\mathrm{t})$, and failure $\mathrm{F}(\mathrm{t})$ [15].

$$
\begin{gathered}
\text { Reliability } R(t)=\frac{N+1-N_{i}}{N+1} \\
C F=F Q_{i}+F Q_{i+1}
\end{gathered}
$$

Hazard Rate $h(t)=\frac{1}{\left(\left(F_{i}-F_{i-1}\right) \times N\right.}$

Failure $\mathrm{F}(\mathrm{t})=1-\mathrm{R}(\mathrm{t})$ 
Table 6. Reliability results of the crankshaft production line

\begin{tabular}{|c|c|c|c|c|c|c|}
\hline No. & Failure Quantity & Total Failure & Surviving Quantity & Reliability $\mathrm{R}(\mathrm{t})$ & Hazard Rate $\mathrm{h}(\mathrm{t})$ & Failure Density $\mathrm{F}(\mathrm{t})$ \\
\hline 1 & 78 & 78 & 8240 & 0.990 & 0.092 & 0.091 \\
\hline 2 & 762 & 840 & 7478 & 0.899 & 0.079 & 0.071 \\
\hline 3 & 598 & 1438 & 6880 & 0.827 & 0.089 & 0.074 \\
\hline 4 & 616 & 2054 & 6264 & 0.753 & 0.158 & 0.119 \\
\hline 5 & 991 & 3045 & 5273 & 0.633 & 0.145 & 0.091 \\
\hline 6 & 765 & 3810 & 4508 & 0.541 & 0.143 & 0.078 \\
\hline 7 & 649 & 4459 & 3859 & 0.463 & 0.185 & 0.085 \\
\hline 8 & 714 & 5173 & 3145 & 0.378 & 0.310 & 0.117 \\
\hline 9 & 977 & 6150 & 2168 & 0.260 & 0.542 & 0.141 \\
\hline 10 & 1177 & 7327 & 991 & 0.119 & 0.638 & 0.076 \\
\hline 11 & 633 & 7960 & 358 & 0.043 & 1 & 0.043 \\
\hline 12 & 358 & 8318 & 0 & 0 & 0 & 0 \\
\hline
\end{tabular}

Table 6 all the information for the crankshaft manufacturing failure is calculated using Eqs. 2, 3,4 , and 5 , depending on the data in Table 6 . The results showed that reliability decreased with time increased. The hazard rate increased by increasing the cumulative failure, and the percentage of product failure increased with increasing time.

\section{CONCLUSIONS}

The most considerable failure was observed in the ring screw, which is 295 times by analyzing the results. Also, through Preto's diagram, it was noticed that the most failure rate occurred in the last four months of the year, equal to $53.8 \%$ of the total failure during one year. By calculations, the most frequent MTBF during the manufacturing process was $0.5 \mathrm{hr}$. Four distribution methods used to check and analyze the crankshaft production line were Weibull, lognormal, exponential, and normal. Every method had a different fitting, and the normal method had the best fitting failure data, equal to 1.367 , depending on the Anderson-Darling (adj).

Furthermore, the empirical approach calculates the production line's reliability to know and predict the crankshaft production line's risks. Results have proved that the reliability of the production process decreased over time. Therefore, elements that contribute to minimizing the reliability of production lines should be identified. Low reliability leads to inefficient manufacturing operations due to increased overall production costs and excessive scrap. For these reasons, the machines and tools' inspection and maintenance processes will increase the production line's reliability. Some recommendations must be carried out for the machines and tools in the production line used in the manufacturing process periodically to avoid downtime during machining processes. These recommendations are to doublecheck: lubricant, temperature, vibration, tools quality, workpiece, tools setup, system power, machining parameters, variables setup, and laborers. In addition, the product line data should also review periodically, such as the most critical issues that cause downtime, the types of product defects, and the places where the defects occur. Also, the reliability of the production process depends on a production line organization, tools failure prediction, adherence by the maintenance and lubrication schedules, maintaining the modernization of the production line by providing it with expertise and modern technology.

\section{REFERENCES}

1. Soltanali H., Rohani A., Tabasizadeh M., Abbaspour-Fard M.H., Parida A. Operational reliability evaluation-based maintenance planning for automotive production line. Quality Technology \& Quantitative Management. 2020; 17(2): 186-202.

2. Tsarouhas P.H., Arvanitoyannis I.S., Varzakas T.H. Reliability and maintainability analysis of cheese (feta) production line in a Greek medium-size company: A case study. Journal of Food Engineering. 2009; 94(3-4): 233-40.

3. Iborra A., Alvarez B., Jimenez C., Fernandez-Merono J.M., Fernandez C., Suardiaz J. Automated Visual Inspection system (AVI) for crankshaft production processes. European Journal of Mechanical and Enviromental Engineering. 2000; 45(1): 29-34. 
4. Accorsi R., Gallo A., Tufano A., Bortolini M., Penazzi S., Manzini R. A tailored maintenance management system to control spare parts life cycle. Procedia Manufacturing. 2019; 1(38): 92-99.

5. dos Reis M.D., Godina R., Pimentel C., Silva F.J., Matias J.C. A TPM strategy implementation in an automotive production line through loss reduction. Procedia Manufacturing. 2019; (1)38: 908-915.

6. Ribeiro I.M., Godina R., Pimentel C., Silva F.J., Matias J.C. Implementing TPM supported by $5 \mathrm{~S}$ to improve the availability of an automotive production line. Procedia Manufacturing. 2019; 38 : 1574-1581.

7. Jasiulewicz-Kaczmarek M., Gola A. Maintenance 4.0 technologies for sustainable manufacturing-an overview. IFAC-PapersOnLine. 2019; 52(10): 91-96.

8. Soltanali H., Rohani A., Tabasizadeh M., Abbaspour-Fard M.H., Parida A. Operational reliability evaluation-based maintenance planning for automotive production line. Quality Technology \& Quantitative Management. 2020; 17(2): 186-202.

9. Zhang D., Zhang Y., Yu M., Chen Y. Reliability defects identification of serial production systems: application to a piston production line. Arabian Journal for Science and Engineering. 2014; 3(12): 9113-9125.
10. Wang F.L., Lin Y. Production effectiveness-based system reliability calculation of serial manufacturing with checking machine. Journal of Computers. 2016; 27(3): 201-211.

11. Cao H., Li D., Yue Y. Root cause identification of machining error based on statistical process control and fault diagnosis of machine tools. Machines. 2017; 5(3): 20 .

12. Hasbullah N.H., Ahmad R. Withdrawn: failure analysis of tyre production process using FMECA method.

13. Pourjavad E., Shirouyehzad H., Shahin A. Analyzing RCM Indicators in Continuous Production Lines A Case Study. International Business Research. 2011; 4(4): 115.

14. Kumar U.D., Crocker J., Chitra T., Saranga H. Reliability and six sigma. Springer Science \& Business Media; 2006.

15. Ebeling C.E. An introduction to reliability and maintainability engineering. Tata McGraw-Hill Education; 2004.

16. Markeset T., Kumar U. R\&M and risk-analysis tools in product design, to reduce life-cycle cost and improve attractiveness. InAnnual Reliability and Maintainability Symposium. 2001 Proceedings. International Symposium on Product Quality and Integrity (Cat. No. 01CH37179), IEEE 2001; 116-122. 